\title{
ENERGY EXPENDITURE OF ATHLETES' ENDURANCE AND STRENGTH IN THE LIGHT OF THE POLISH ENERGY INTAKE STANDARDS
}

\author{
BARBARA FRĄCZEK ${ }^{1}$, ANDRZEJ GRZELAK ${ }^{2}$, and ANDRZEJ T. KLIMEK ${ }^{2}$
}

University of Physical Education in Krakow, Kraków, Poland

${ }^{1}$ Faculty of Physical Education and Sport, Institute of Biomedical Sciences, Department of Sports Medicine and Human Nutrition

${ }^{2}$ Faculty of Physical Education and Sport, Institute of Biomedical Sciences, Department of Physiology and Biochemistry

\begin{abstract}
Objectives: The purpose of the study was to estimate training energy expenditure (TEE) and daily energy expenditure (DEE) in the Polish elite athletes engaged in endurance sports and power sports, and to compare their levels with the Polish energy intake standards. Material and Methods: The study sample consisted of 30 athletes (15 women and 15 men) whose energy expenditure was estimated based on heart rate monitoring. Results: The mean values of DEE obtained for women engaged in endurance sports (WE - women endurance) and power sports (WP - women power) were $3201 \pm 533 \mathrm{kcal}$ and $3217 \pm 554 \mathrm{kcal}$, respectively. In the group of male athletes, the respective values were $4518 \pm 717 \mathrm{kcal}$ for endurance athletes (ME - men endurance) and $4459 \pm 837 \mathrm{kcal}$ for power athletes (MP - men power). The mean values of TEE for female athletes were $819 \pm 240 \mathrm{kcal}(\mathrm{WE})$ and $1047 \pm 248 \mathrm{kcal}(\mathrm{WP})$. Those obtained for male athletes were significantly higher: $1440 \pm 675 \mathrm{kcal}(\mathrm{ME})$ and $1337 \pm 331 \mathrm{kcal}(\mathrm{MP})$. Conclusions: Unlike the demands of particular sport disciplines, an athlete's sex proved to be a factor causing significant differences between the TEE and DEE of athletes representing different sport disciplines. Individual athletes were found to differ significantly in their demand for energy, which in some cases was considerably different from what energy intake standards propose. Int J Occup Med Environ Health. 2019;32(1):1-13
\end{abstract}

Key words:

athletes, heart rate monitoring, daily energy expenditure, training energy expenditure, endurance sports, power sports

\section{INTRODUCTION}

Sustainable energy balance is one of the main objectives of nutritional support for athletes training to increase their exercise capacity. For the balance to be achieved and maintained, food energy intake must correspond to the current demand for energy. Otherwise, energy balance may be disturbed and may lead to unfavorable changes in athletes' body mass (BM), composition and function, reducing their capacity to exercise [1-4]. The planning of nutritional strategies emphasizing optimal exercise capacity should therefore start with the determination of an individual's energy requirements by estimating his or her daily energy expenditure (DEE). The DEE of competitive athletes depends to a great extent on how much energy they use during training. Because of the demands of the sport discipline and the stage of the training cycle, training

Funding: this research was supported by the University of Physical Education in Krakow (project No. 35/MIN/INB/2013 entitled "Analysis of the training and daily energy expenditure athletes depending on the sport discipline and applied measurement method," project manager: Andrzej Grzelak).

Received: November 8, 2017. Accepted: April 19, 2018.

Corresponding author: Barbara Frączek, University of Physical Education in Krakow, Department of Sports Medicine and Human Nutrition, al. Jana Pawła II 78, 31-571 Kraków, Poland (e-mail: barbara.fraczek@awf.krakow.pl). 
energy expenditure (TEE) may be within the range of $20-56 \%$ of the DEE that in elite athletes may amount to $7000 \mathrm{kcal}$ [2]. The TEE and DEE levels having been determined, the optimal energy requirements of an individual may be assessed, which are necessary to monitor energy balance. It is estimated that an adult person regularly exceeding the recommended average daily energy intake of 2000-3000 kcal by only 3\% gains 3-4 kg in weight a year. This shows the importance of matching precisely athletes' energy intake with their current energy expenditure.

There are several methods that researchers use to assess physical activity and energy expenditure, each having its advantages and drawbacks [5-7]. It is considered that the most accurate of them are direct calorimetry, the doublylabelled water (DLW) method and the indirect calorimetry method [5]. Because of their limitations (direct calorimetry requires the laboratory setting, indirect calorimetry makes the subject wear a mask connected with a breathing gas analyzer, and the DLW cannot be used for measuring energy expenditure during short training units) and high costs, they are, however, rarely used for measuring the DEE and TEE in athletes.

The heart-rate monitoring method taking advantage of the linear relationship between heart rate (HR) and oxygen uptake $\left(\mathrm{VO}_{2}\right)$ is used more frequently. It is preferred by many researchers because it is relatively accurate, inexpensive and readily available, causes little discomfort to the tested person and allows the measurements to be made under natural conditions [8-21]. Because of these characteristics, it was also selected for this study. Accuracy of the HR method using the actual maximum oxygen uptake and actual maximum heart rate was verified, e.g., in the study of Crouter et al. [16] who stated, that when the predicted values of maximum oxygen uptake $\left(\mathrm{VO}_{2 \max }\right)$ and maximum heart rate $\left(\mathrm{HR}_{\max }\right)$ were used, the Polar software calculating energy expenditure provided a rough estimate of the EE during running, rowing and cycling, but using the actual values for $\mathrm{VO}_{2 \max }$ and $\mathrm{HR}_{\max }$ reduced the individual error scores.
Despite the increasing number of international publications on energy expenditure for athletes representing different sports and events [8,18-20,22-26], only few research reports present the real levels of the TEE and DEE for Polish competitive athletes. Therefore, this study was undertaken to assess the TEE of Polish competitive athletes engaged in different types of endurance and power sports with respect to their DEE. Additionally, because the Polish energy intake standards for persons who are physically very active are rather general and thus hinder the planning of effective dietary regimes [27], the study has also sought to establish the relationship between athletes' TEE and DEE and their sport disciplines, and compared the results with the Polish energy intake standards.

\section{MATERIAL AND METHODS}

The sample consisted of 30 elite Polish athletes (aged 20-34 years old; 15 women and 15 men) who were divided into 4 groups using the criterion of sex and sport discipline. Group 1 (WE - women endurance; $\mathrm{N}=7$ ) included female athletes engaged in endurance sports (speed skating [N = 3], cross-country skiing, steeplechase, off-road cycling). Group 2 (WP - women power; $\mathrm{N}=8$ ) was formed of female power athletes (volleyball $[\mathrm{N}=2$ ], alpine skiing [N = 2], middle-distance running, sport climbing, tennis, kayaking). Group 3 ( $\mathrm{ME}$ - men endurance; $\mathrm{N}=7$ ) included male endurance athletes (rowing $[\mathrm{N}=2]$, race walking $[\mathrm{N}=2]$, cross-country skiing, biathlon, off-road cycling). Group 4 ( MP - men power; $\mathrm{N}=8$ ) consisted of male power athletes (kayaking [ $\mathrm{N}=2$ ], middle-distance running, fencing, speed skating, handball, volleyball, and ice hockey).

The study was carried out during the preparatory period of the annual training cycle. The training protocol followed by individual athletes was designed in line with the demands of their sport, training objectives and the stage of the preparatory period.

Before admission into the testing, BM, percent of body fat $(\mathrm{BF})$ and fat free mass (FFM) were examined using 
a body composition analyzer Akern BodyComp MF+ (Italy). Subjects' BM was measured using a Tanita TBF-300 (Japan). The study was divided into 2 parts. Participants first performed incremental exercise tests to volitional exhaustion in the laboratory setting to record their maximum oxygen uptake $\left(\mathrm{VO}_{2 \max }\right)$ and maximum heart rate $\left(\mathrm{HR}_{\max }\right)$. The testing equipment was selected to match the demands of their respective sports. Accordingly, the rowers exercised on the Dansprint kayak ergometer.

The initial workloads of $200 \mathrm{~W}$ for men and $100 \mathrm{~W}$ for women were increased every 2 min by $30 \mathrm{~W}$. To test the kayakers, the upper body ergometer Cyclus2 was used. The initial workloads of $50 \mathrm{~W}$ for men and $40 \mathrm{~W}$ for women were adjusted upwards every 2 min by $20 \mathrm{~W}$. The race walkers exercised on a treadmill made by HP-Cosmos GmbH. Walking speed that started with $10 \mathrm{~km} / \mathrm{h}$ for men and $8 \mathrm{~km} / \mathrm{h}$ for women was increased every $2 \mathrm{~min}$ by $1 \mathrm{~km} / \mathrm{h}$. After the speed of $14 \mathrm{~km} / \mathrm{h}$ and $12 \mathrm{~km} / \mathrm{h}$ was achieved, exercise intensity was raised every 2 min by increasing the treadmill elevation by $1^{\circ}$. The cyclists exercised on the cycloergometer Jaeger ER 900. The initial workloads of $100 \mathrm{~W}$ for men and $80 \mathrm{~W}$ for women were increased every 2 min by $20 \mathrm{~W}$ until the tested athlete's failure to maintain the pedaling speed of $60 \mathrm{r} / \mathrm{min}$ set by the metronome. The other participants performed a treadmill test. The initial belt speed of $2.7 \mathrm{~m} / \mathrm{s}$ for men and $2.4 \mathrm{~m} / \mathrm{s}$ for women was increased every $2 \mathrm{~min}$ by $0.3 \mathrm{~m} / \mathrm{s}$.

The level of respiratory system parameters was recorded using the computerized ergospirometer Start-2000-M (MES, Poland). Training energy expenditure and the DEE were assessed in the study participants by having them wear heart rate monitors (Polar Electro, Finland) $24 \mathrm{~h} /$ day over a period of 7 days. The devices used in the study, RS-400, were provided with the "OwnCal” software calculating energy expenditure from variables such as sex, age, body height, BM, maximum heart rate $\left(\mathrm{HR}_{\max }\right)$, maximum oxygen uptake $\left(\mathrm{VO}_{2 \max }\right)$, and a level of physical activity, and from heart rate monitored on an ongoing basis [16].
The statistical tools used for performing the mathematical and statistical analysis of the data and plotting the graphs were Microsoft Excel 2010 and Statistica 10.0. Variables selected for the analysis were characterized using the following descriptive statistics: arithmetic average $(\overline{\mathrm{x}})$, minimal value (min.), maximal value (max) and standard deviation (SD). To find out if the values of the analyzed variables were significantly different between the groups of male and female athletes, the Student's t-test was applied. Values that failed to meet its assumptions were subjected to the non-parametric Mann-Whitney U test. Differences in results obtained for WE, WP, ME and MP were tested with ANOVA. The statistically significant differences were compared using the Tukey post hoc test. Whenever ANOVA assumptions were not met, the Kruskal-Wallis test and post hoc multiple comparison tests, the non-parametric equivalents of ANOVA, were applied. For all statistical tests, values and coefficients the level of statistical significance was set at $p<0.05$.

\section{RESULTS}

The Table 1 contains the values of anthropometric and physiological variables characterizing the male and female participants of the study. The mean BMI of the female athletes was $21.4 \mathrm{~kg} / \mathrm{m}^{2}$, the mean BM $-63.7 \mathrm{~kg}$, including $50.5 \mathrm{~kg}$ of lean body mass (LBM), and fat mass accounted for $21.2 \%$. Their mean $\mathrm{HR}_{\max }$ and $\mathrm{VO}_{2 \max }$ recorded during the graded exercise test were $195 \mathrm{bpm}$ and $54.2 \mathrm{ml} / \mathrm{kg} / \mathrm{min}$, respectively. The mean values of most anthropometric variables were slightly higher for female power athletes compared with female endurance athletes (except for fat content) but the former had lower mean values of $\mathrm{HR}_{\max }$ and $\mathrm{VO}_{2 \max }$. The differences were not statistically significant (Table 2). The mean BM of male athletes was $75.2 \mathrm{~kg}$ (66 kg of LBM and $12.6 \%$ of BF), mean height $-182 \mathrm{~cm}$ and BMI $-22.7 \mathrm{~kg} / \mathrm{m}^{2}$. The mean $\mathrm{HR}_{\text {max }}$ and $\mathrm{VO}_{2 \max }$ were calculated at $196 \mathrm{bpm}$ and $58.7 \mathrm{ml} / \mathrm{kg} / \mathrm{min}$. The mean values of all variables but age, 
Table 1. Anthropometric and physiological indicators for the Polish elite athletes during the preparatory period of the annual training cycle in 2013

\begin{tabular}{|c|c|c|c|c|c|c|c|c|}
\hline Group & $\begin{array}{c}\text { Age } \\
\text { [years] }\end{array}$ & $\begin{array}{l}\mathrm{BH} \\
{[\mathrm{cm}]}\end{array}$ & $\begin{array}{l}\mathrm{BM} \\
{[\mathrm{kg}]}\end{array}$ & $\begin{array}{c}\text { BMI } \\
{\left[\mathrm{kg} / \mathrm{m}^{2}\right]}\end{array}$ & $\begin{array}{l}\mathrm{BF} \\
{[\%]}\end{array}$ & $\begin{array}{c}\text { FFM } \\
{[\mathrm{kg}]}\end{array}$ & $\begin{array}{l}\mathrm{HR}_{\text {max }} \\
{[\mathrm{bpm}]}\end{array}$ & $\underset{[\mathrm{ml} / \mathrm{kg} / \mathrm{min}]}{\mathrm{VO}_{\max }}$ \\
\hline \multicolumn{9}{|l|}{ Women } \\
\hline \multicolumn{9}{|l|}{ WE } \\
\hline M & 23.1 & 172.4 & 62.9 & 21.1 & 22.2 & 49.2 & 196.3 & 55.6 \\
\hline SD & 4.98 & 4.20 & 4.88 & 1.51 & 4.84 & 4.97 & 3.95 & 2.12 \\
\hline min. & 20.0 & 166.0 & 56.0 & 18.8 & 14.6 & 44.2 & 188.0 & 53.4 \\
\hline $\max$ & 34.0 & 177.0 & 70.0 & 22.9 & 26.5 & 57.4 & 200.0 & 60.1 \\
\hline \multicolumn{9}{|l|}{ WP } \\
\hline $\mathrm{M}$ & 25.4 & 172.5 & 64.5 & 21.7 & 20.3 & 51.7 & 194.3 & 53.0 \\
\hline SD & 3.81 & 7.89 & 5.66 & 1.42 & 5.61 & 3.73 & 2.92 & 2.27 \\
\hline $\min$. & 20.0 & 159.0 & 57.0 & 18.8 & 12.9 & 45.9 & 189.0 & 49.1 \\
\hline $\max$ & 32.0 & 184.0 & 73.0 & 23.6 & 29.1 & 56.8 & 198.0 & 56.1 \\
\hline \multicolumn{9}{|l|}{ Total } \\
\hline M & 24.3 & 172.5 & 63.7 & 21.4 & 21.2 & 50.5 & 195.2 & 54.2 \\
\hline SD & 4.39 & 6.22 & 5.19 & 1.43 & 5.17 & 4.38 & 3.47 & 2.53 \\
\hline $\min$. & 20.0 & 159.0 & 56.0 & 18.8 & 12.9 & 44.2 & 188.0 & 49.1 \\
\hline $\max$ & 34.0 & 184.0 & 73.0 & 23.6 & 29.1 & 57.4 & 200.0 & 60.1 \\
\hline \multicolumn{9}{|l|}{ Men } \\
\hline \multicolumn{9}{|l|}{$\mathrm{ME}$} \\
\hline M & 24.3 & 181.9 & 71.4 & 21.6 & 13.3 & 61.9 & 195.4 & 61.0 \\
\hline SD & 4.92 & 4.30 & 4.89 & 1.09 & 4.22 & 5.54 & 3.87 & 5.63 \\
\hline $\min$. & 21.0 & 174.0 & 62.0 & 20.2 & 8.1 & 53.8 & 189.0 & 54.3 \\
\hline $\max$ & 34.0 & 186.0 & 76.0 & 23.5 & 20.2 & 70.0 & 201.0 & 69.0 \\
\hline \multicolumn{9}{|l|}{ MP } \\
\hline $\mathrm{M}$ & 22.0 & 182.1 & 78.5 & 23.6 & 12.0 & 69.6 & 196.6 & 56.7 \\
\hline SD & 1.07 & 5.28 & 7.62 & 1.55 & 3.37 & 5.27 & 1.85 & 3.92 \\
\hline min. & 20.0 & 177.0 & 69.0 & 21.3 & 7.0 & 64.3 & 193.0 & 52.8 \\
\hline $\max$ & 23.0 & 190.0 & 94.0 & 26.6 & 15.3 & 80.3 & 199.0 & 63.4 \\
\hline \multicolumn{9}{|l|}{ Total } \\
\hline $\mathrm{M}$ & 23.1 & 182.0 & 75.2 & 22.7 & 12.6 & 66.0 & 196.1 & 58.7 \\
\hline SD & 3.51 & 4.68 & 7.25 & 1.67 & 3.71 & 6.53 & 2.91 & 5.12 \\
\hline min. & 20.0 & 174.0 & 62.0 & 20.2 & 7.0 & 53.8 & 189.0 & 52.8 \\
\hline $\max$ & 34.0 & 190.0 & 94.0 & 26.6 & 20.2 & 80.3 & 201.0 & 69.0 \\
\hline
\end{tabular}

BF - body fat; BH - body height; BM - body mass; BMI - body mass index; FFM - fat free mass; $\mathrm{HR}_{\text {max }}$ - maximum heart rate; ME - men endurance; $\mathrm{MP}$ - men power; $\mathrm{WE}$ - women endurance; $\mathrm{WP}$ - women power; $\mathrm{VO}_{2 \max }$ - maximum oxygen uptake.

fat content and maximum oxygen uptake were higher for for male and female athletes were significantly different the MP group than for the ME group, but only BMI and LBM were found to be significantly different between (Table 2). the 2 groups. The values of most variables determined In the Table 3, the minimum and maximum means of the TEE and DEE, their SDs, and the differences be- 

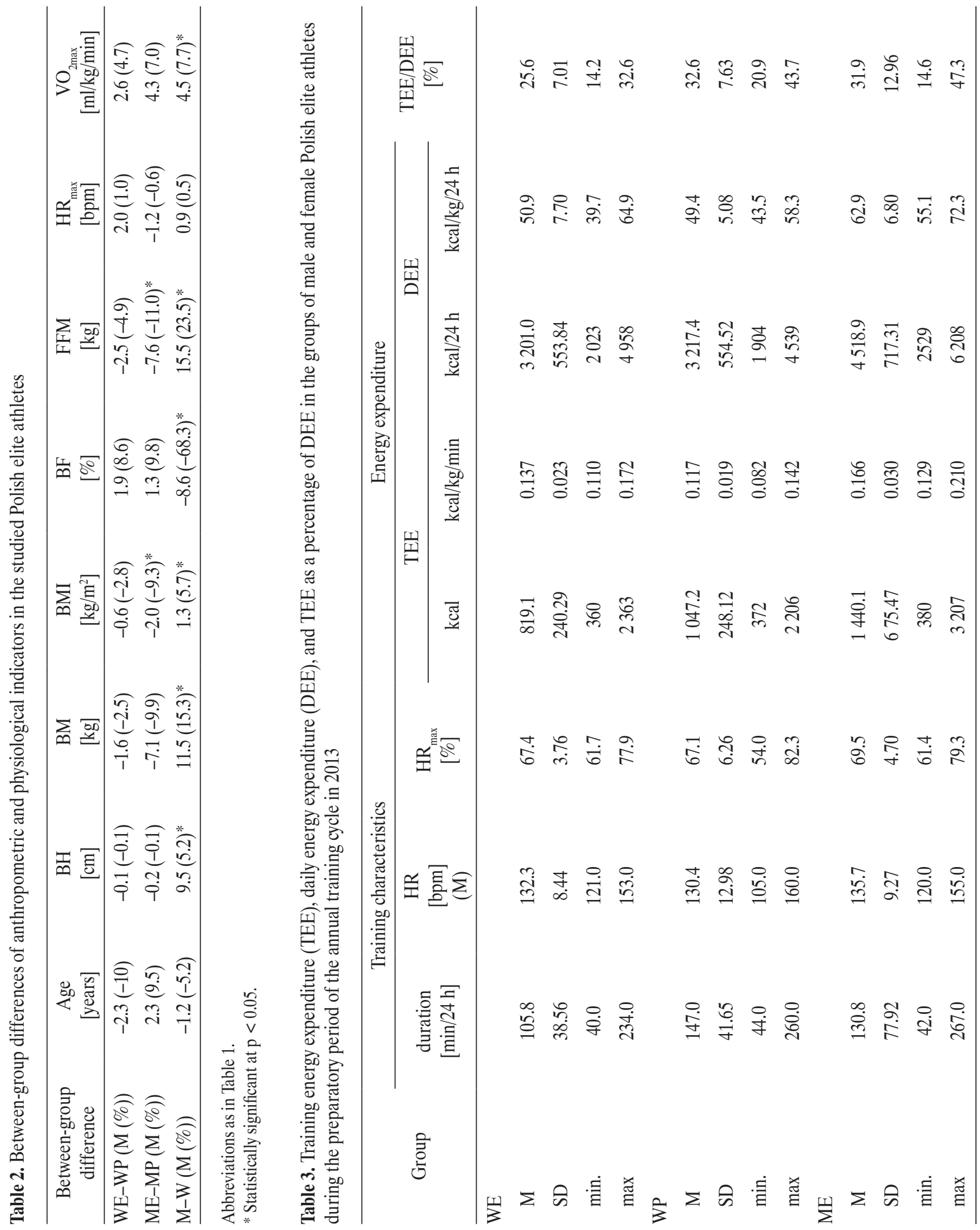


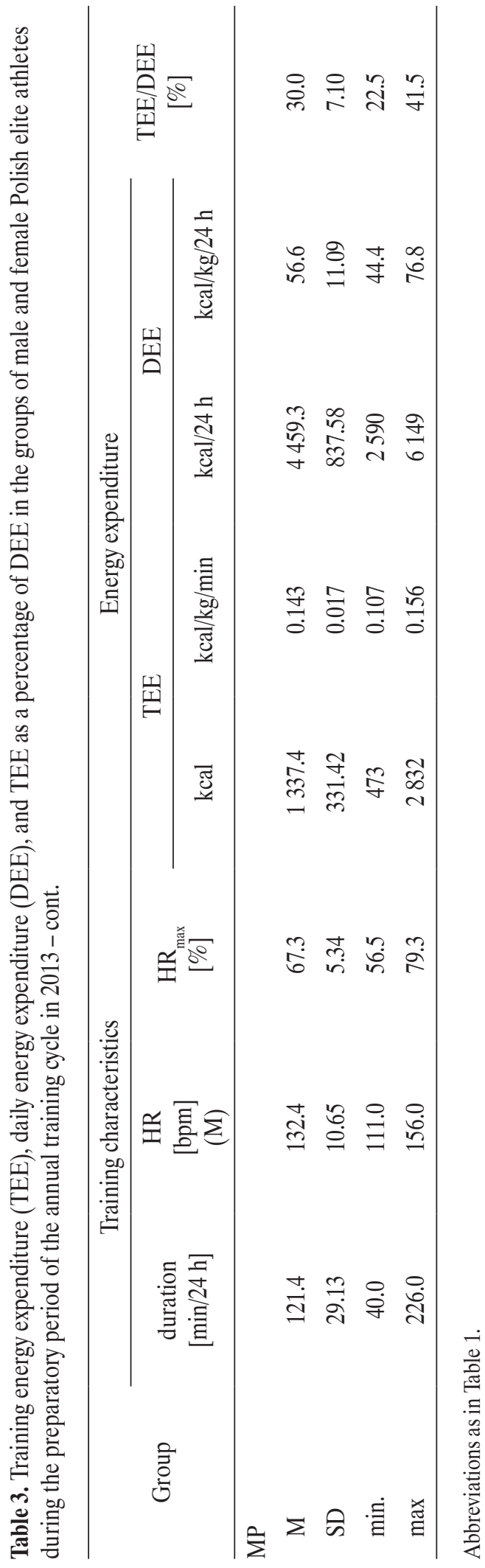

tween the means are shown. Subjects' 7-day TEE as well as DEE values were aggregated, so SDs represented the variability. The female athletes' DEE ranges widely from $1904 \mathrm{kcal}$ to $4958 \mathrm{kcal}$ and its mean values amount to $3201 \pm 533.84 \mathrm{kcal}$ (WE) and $3217.4 \pm 554.52 \mathrm{kcal}(\mathrm{WP})$. The relative DEE (per kilogram of $\mathrm{BM}$ ) also shows variations ranging from $39.7 \mathrm{kcal} / \mathrm{kg}$ to $64.9 \mathrm{kcal} / \mathrm{kg}$. With all these differences, the mean values of the DEE calculated for the groups of female athletes are similar $(50.9 \pm 7.7 \mathrm{kcal} / \mathrm{kg}$ in the WE group and $49.4 \pm 5.08 \mathrm{kcal} / \mathrm{kg}$ in the WP group). The statistical analysis did not show the 2 groups to differ significantly in the mean DEE (absolute or relative).

The male athletes' DEE ranges 2529-6208 kcal. Its mean values are $4518.9 \pm 717.31 \mathrm{kcal}(\mathrm{ME})$ and $4459.3 \pm$ $837.58 \mathrm{kcal}$ (MP). The relative DEE varying between $44.4-76.8 \mathrm{kcal} / \mathrm{kg}$ has mean values of $62.9 \pm$ $6.80 \mathrm{kcal} / \mathrm{kg}(\mathrm{ME})$ and $56.6 \pm 11.09 \mathrm{kcal} / \mathrm{kg}(\mathrm{MP})$. The mean values of the DEE (relative and absolute) calculated for the 2 groups are not significantly different.

However, male and female athletes have been found to differ from each other. The mean absolute values of the DEE are greater for men than for women by around 1200-1300 kcal, with all differences being statistically significant. The relative DEE of the ME group is higher by $12 \mathrm{kcal} / \mathrm{kg}$ and $13.5 \mathrm{kcal} / \mathrm{kg}$ from that obtained for the WE and WP groups. In this case, too, the differences are statistically significant.

The female athletes' TEE ranges $360-2363 \mathrm{kcal} / 24 \mathrm{~h}$. Its mean values have been estimated at $819.1 \pm 240.29 \mathrm{kcal} /$ $24 \mathrm{~h}$ (WE) and $1047.2 \pm 248.12 \mathrm{kcal} / 24 \mathrm{~h}$ (WP). The difference of $228 \mathrm{kcal}$ is not statistically significant. The mean TEE (per $\mathrm{kg}$ of BM and min of training time) is higher in the first group $(0.137 \mathrm{kcal}$ vs. $0.117 \mathrm{kcal})$ but the difference is not statistically significant again. The male athletes' TEE varies from $380 \mathrm{kcal}$ to $3207 \mathrm{kcal}$, with its mean values being slightly higher for the ME group than for the MP group in both absolute terms $(1440 \pm 675 \mathrm{kcal}$ 
Table 4. Differences in between-group means training energy expenditure (TEE), daily energy expenditure (DEE), and TEE as a percentage of DEE in the groups of male and female Polish elite athletes

\begin{tabular}{|c|c|c|c|c|c|c|c|c|}
\hline \multirow{3}{*}{$\begin{array}{l}\text { Between- } \\
\text { group } \\
\text { difference }\end{array}$} & \multicolumn{3}{|c|}{$\begin{array}{l}\text { Training characteristics } \\
\text { (M) }\end{array}$} & \multicolumn{4}{|c|}{$\begin{array}{l}\text { Energy expenditure } \\
(\mathrm{M}(\%))\end{array}$} & \multirow{3}{*}{$\begin{array}{c}\mathrm{TEE} / \mathrm{DEE} \\
{[\%]}\end{array}$} \\
\hline & \multirow{2}{*}{$\begin{array}{c}\text { duration } \\
{[\mathrm{min} / 24 \mathrm{~h}]}\end{array}$} & \multirow{2}{*}{$\begin{array}{c}\mathrm{HR} \\
{[\mathrm{bpm}]}\end{array}$} & \multirow{2}{*}{$\begin{array}{c}\mathrm{HR}_{\max } \\
{[\%]}\end{array}$} & \multicolumn{2}{|c|}{ TEE } & \multicolumn{2}{|c|}{ DEE } & \\
\hline & & & & kcal & $\mathrm{kcal} / \mathrm{kg} / \mathrm{min}$ & kcal & $\mathrm{kcal} / \mathrm{kg} / \mathrm{min}$ & \\
\hline WE-WP & -41.2 & 1.9 & 0.3 & $-228.1(-21.8)$ & 0.020 (14.6) & $-16.4(-0.5)$ & $1.5(2.9)$ & -7 \\
\hline ME-MP & 9.4 & 3.3 & 2.2 & $102.7(7.13)$ & $0.023(13.9)$ & $59.6(1.3)$ & $6.3(10)$ & 1.9 \\
\hline ME-WE & 25 & 3.4 & 2.1 & $621(43.1)^{*}$ & $0.029(17.5)$ & $1317.9(29.2)^{*}$ & $12(19.1)^{*}$ & 6.3 \\
\hline MP-WP & -25.6 & 2.0 & 0.2 & $290.2(21.7)^{*}$ & $0.026(18.2)$ & $1241.9(27.8)^{*}$ & $7.2(12.7)$ & -2.6 \\
\hline ME-WP & -16.2 & 5.3 & 2.4 & $392.9(27.3)^{*}$ & $0.049(29.5)^{*}$ & $1301.5(28.8)^{*}$ & $13.5(21.5)^{*}$ & -0.7 \\
\hline MP-WE & 15.6 & 0.1 & -0.1 & $518.3(38.7)^{*}$ & $0.006(4.2)$ & $1258.3(28.2)^{*}$ & $5.7(10.1)$ & -2.6 \\
\hline
\end{tabular}

Abbreviations as in Table 1.

* Statistically significant at $\mathrm{p}<0.05$.

vs. $1337.4 \pm 331 \mathrm{kcal})$ and relative terms $(0.166 \mathrm{kcal} / \mathrm{kg} / \mathrm{min}$ vs. $0.143 \mathrm{kcal} / \mathrm{kg} / \mathrm{min})$. The differences are not insignificant in either case.

An analysis did not show factors influencing the energy cost of exercise, i.e., the mean duration of training $(r=0.77$; $\mathrm{p}<0.05)$ and mean heart rate $(\mathrm{r}=0.69 ; \mathrm{p}<0.05)$ to cause significant differences between groups (Table 4).
In the Figure 1, the relations between the TEE and DEE of male and female athletes are presented by sport discipline. The mean values of the ratios between the TEE and DEE are similar (25.6\% [WE], 32.6\% [WP], 31.9\% [ME] and $30 \%[\mathrm{MP}])$ and the estimated differences are not statistically significant (Table 3). As far as individual athletes are concerned, the lowest TEE as a percentage share of

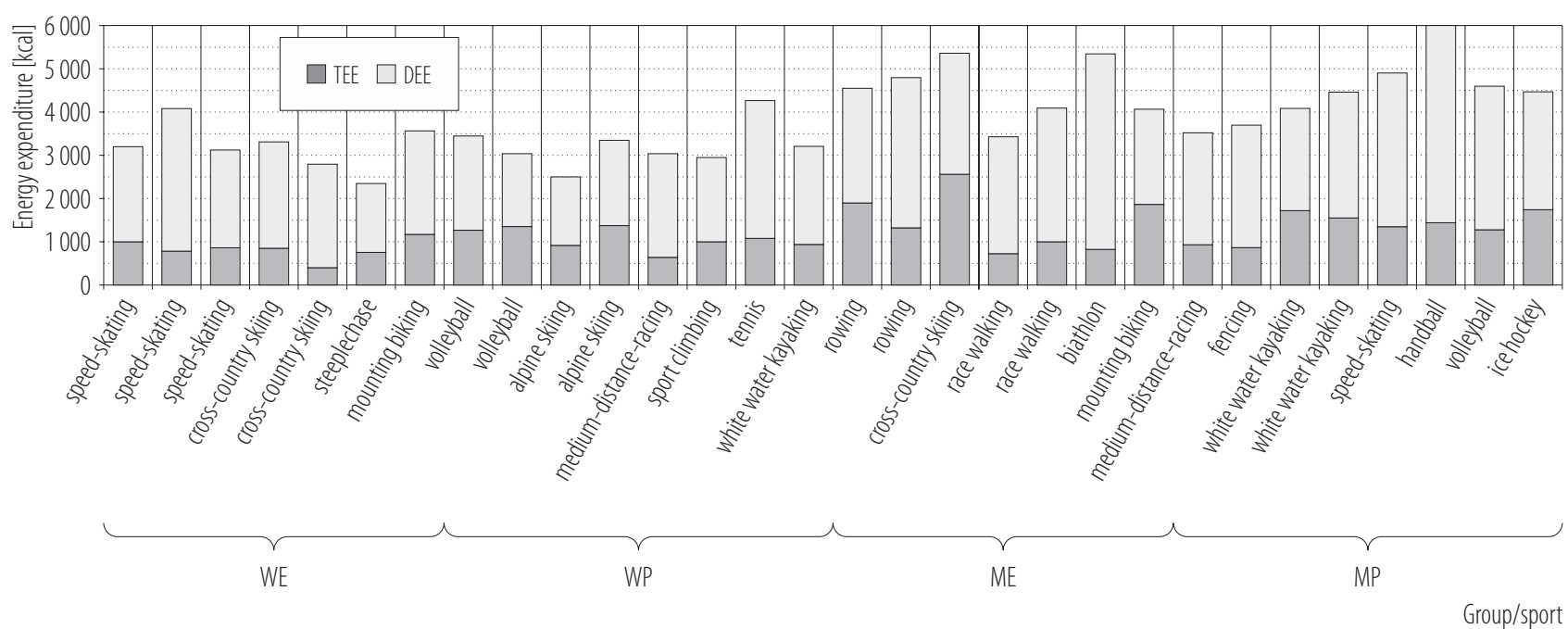

Abbreviations as in Table 1.

Figure 1. Training energy expenditure (TEE) and daily energy expenditure (DEE) of the Polish elite athletes by type of sport during the preparatory period of the annual training cycle in 2013 


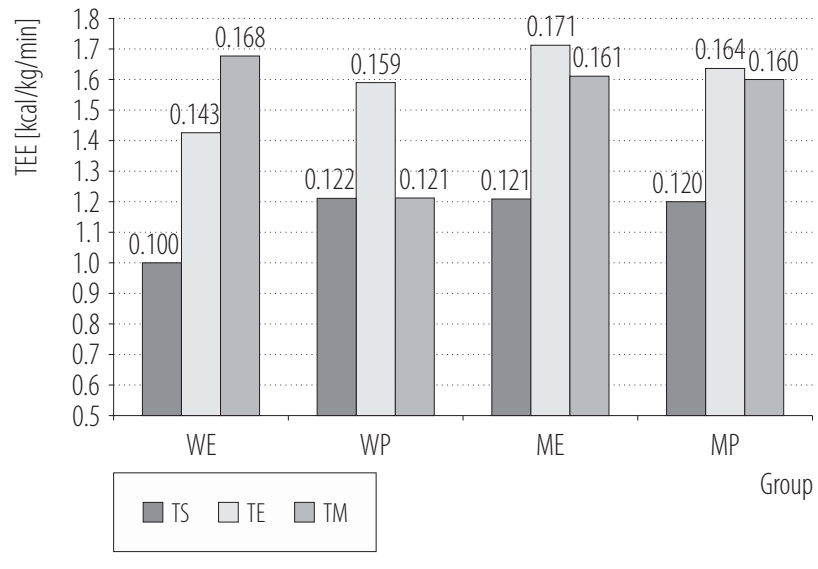

$\mathrm{TE}$ - endurance training; TM - mixed training with endurance, and/or speed and/or strength components; TS - strength training. Other abbreviations as in Table 1.

Figure 2. Training energy expenditure (TEE) by group and type of training in the Polish elite athletes during the preparatory period of the annual training cycle in 2013

the DEE was determined for a female cross-country skier $(14.2 \%)$ and the highest - for a male athlete in the same sport discipline $(47.3 \%)$.

In the Figure 2, the mean energy expenditures are compared by type of training. The lowest energy cost of training has been determined for strength training (TS) in the group of female endurance athletes $(0.1 \mathrm{kcal} / \mathrm{kg} / \mathrm{min})$; the other groups of female athletes were similar in the TS-related energy cost (around $0.121 \mathrm{kcal} / \mathrm{kg} / \mathrm{min}$ ). The energy cost of mixed training (TM) for women representing speed-strength sports amounts to $0.121 \mathrm{kcal} / \mathrm{kg} / \mathrm{min}$, so it is similar to the energy cost of TS. Its values estimated for other groups are much higher. The highest value, $0.168 \mathrm{kcal} / \mathrm{kg} / \mathrm{min}$, has been obtained for the WE group. The energy cost of endurance training (TE) varies from $0.143 \mathrm{kcal} / \mathrm{kg} / \mathrm{min}$ (WE) to $0.171 \mathrm{kcal} / \mathrm{kg} / \mathrm{min}$ (ME). The results of the statistical analysis do not show significant differences between the type of training and the TEE in the groups of male athletes (ME and MP). As far as female athletes are concerned, significant differences between the energy cost of TS and TM are noticeable for women engaged in endurance sports (WE). The comparison of the TEE values for groups of male and female athletes shows significant differences between the strength training TEE of female endurance athletes and the TEE related to predominantly endurance training in both groups of male athletes $(p<0.05)$ as well as between the mixed training TEE estimated for female power athletes and the endurance training TEE determined for male endurance athletes $(p=0.006)$.

The values of the DEE were juxtaposed with the Polish energy intake standards (Table 5) created for the general public [23] with respect to physical activity levels (PAL) of 1.75-2.4, and for athletes representing different sport disciplines [2]. The most appropriate for mean DEEs calculated for groups WE and WP proved to be PAL 2.2 of the general standards, and for male athletes the PAL 2.4. The Figure 3 illustrates the numbers and percentages of athletes whose mean DEE corresponds best with energy intake standards developed for different levels of physical activity. For 3 athletes ( 2 women and 1 man) the PAL 1.75 standards are the most appropriate, for 2 female athletes these are PAL 2.0 standards, and for 5 women and 3 men

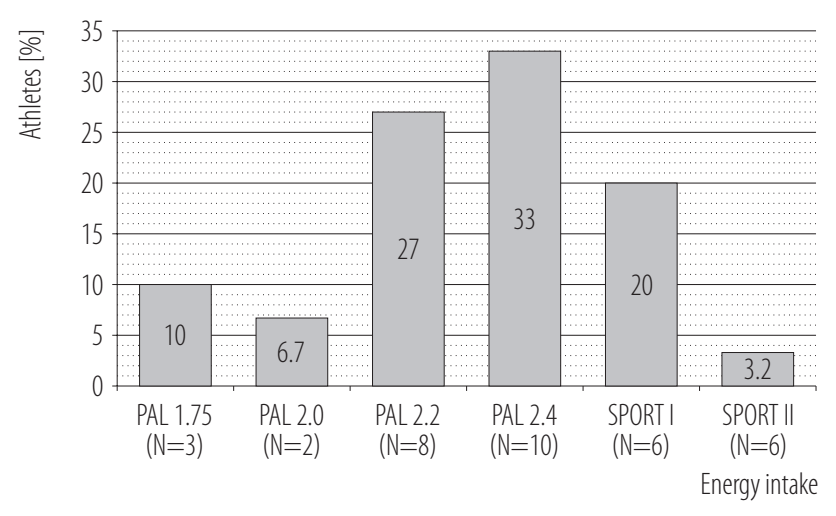

PAL 1.75-2.4 - physical activity levels: general energy intake standards for persons with moderate and high levels of physical activity; SPORT - energy intake standards for the athletes: I) light training period, II) intense training period.

Figure 3. Athletes with daily energy expenditure (DEE) best matching particular energy intake standards in the Polish elite athletes during the preparatory period of the annual training cycle in 2013 
the PAL 2.2 standards may be recommended. The DEE of most athletes ( 4 women and 6 men) is best matched by energy intake standards for PAL 2.4. In the case of 7 participants (2 women and 5 men), standards dedicated to athletes are the most suitable.

\section{DISCUSSION}

The analysis of individual data reveals significant differences in the DEE of athletes representing different sport disciplines during the preparatory period of the annual training cycle. For female athletes it varies from $1904 \mathrm{kcal}$ to $4958 \mathrm{kcal}$ and for male athletes - from $2529 \mathrm{kcal}$ to $6208 \mathrm{kcal}$. As regards the TEE, the respective ranges are $360 \mathrm{kcal}$ and $2363 \mathrm{kcal}$ and $380 \mathrm{kcal}$ and $3207 \mathrm{kcal}$. The ratio of the TEE to DEE takes values 14.2-47.3\%. Differences between individual athletes may be explained through many interrelated factors, such as sex, BM, and the special requirements of their sport, but also in terms of the stage of the preparatory period, training intensity and duration, and physical activity during the non-training period.

The mean values of the DEE and TEE were calculated with respect to athletes' sex and sport discipline (requiring endurance or power). Sport alone does not significantly differentiate male athletes from female athletes, which implies that the demands of particular disciplines do not influence the absolute means of energy expenditure but sex contributes to significant between-sex differences in the absolute values of the DEE and TEE (higher in men). The probable reason is much greater body height, BM, BMI and LBM in the latter. The comparison of male and female athletes' relative DEE and TEE shows that only some between-group differences are statistically significant. The relative TEE of male endurance athletes is significantly higher than that estimated for female athletes representing speed-strength sports, and their relative DEE significantly exceeds relative DEE obtained for both groups of female athletes (by 19.1\% [WE] and 21.5\% [WP]). The differences are probably due to male endur-

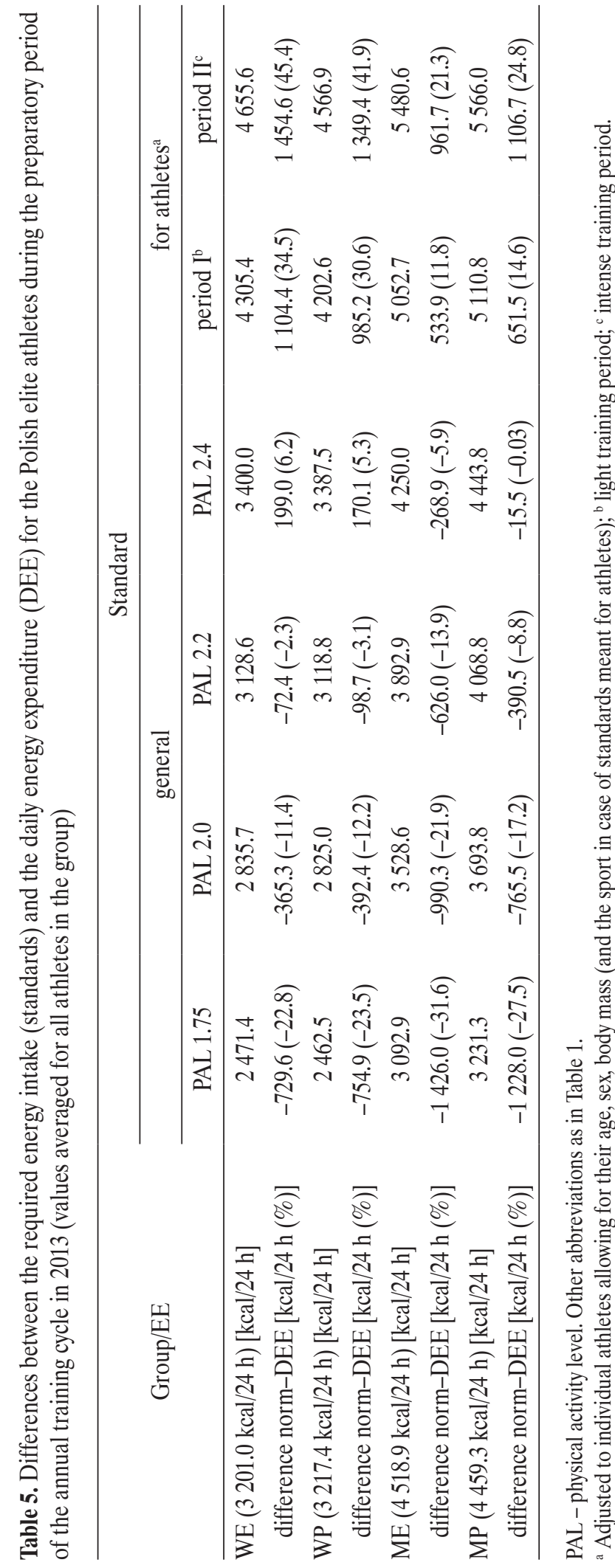


ance athletes and both groups of female athletes differing in BM. The mean BM of athletes in the MP group is greater by $14.8 \mathrm{~kg}$ and $7.1 \mathrm{~kg}$ as compared with female athletes and male athletes in the ME group, meaning that their relative energy expenditure (per $\mathrm{kg}$ of $\mathrm{BM}$ ) is lower than in endurance athletes and insignificantly different from that estimated for groups of female athletes. This leads to a conclusion that relative energy expenditure, which largely depends on BM, is influenced by an athlete's sex and sport discipline that expects athletes to have specific BM. Because the mean values of the TEE are not significantly different between the groups of both male and female athletes it may be concluded that during the preparatory phase of training, male and female athletes engaged in endurance and power sports have similar levels of the TEE (slightly higher for endurance athletes). A probable reason for this similarity is comparable intensity and duration of their training. The statistical analysis did not find these 2 factors, both of which have major influence on energy expenditure, to be significantly different between groups [3]. For most athletes, strength training and endurance training involved the lowest and highest energy cost, respectively.

The findings of this study during the preparatory period of the annual training cycle, relate to the results obtained by Bajerska-Jarzębowska et al. [13], who estimated energy expenditure in 7 Polish race-walkers aged 21 years old in the preparatory and competition periods also by monitoring participants' heart rate for $24 \mathrm{~h} /$ day. The mean values of the TEE were $2344 \mathrm{kcal}$ and $2073 \mathrm{kcal}$, respectively, and the TEE in relation to the DEE exceeded $50 \%$ in both periods. The mean DEE was estimated at $4209 \mathrm{kcal}$ and $3912 \mathrm{kcal}$. In this study, which was conducted in the preparatory period, 2 race-walkers had the TEE in the range of 380-1826 kcal and 556-1485 kcal (the means were $717 \mathrm{kcal}$ and $989 \mathrm{kcal}$ ), which accounted for 14-38\% of their DEE (the respective means for the ME group were $19 \%, 24 \%$, and $31.9 \%$ ). The DEE of the study participants ranged 2824-4809 kcal, with weekly means of $3417 \mathrm{kcal}$ and $4092 \mathrm{kcal}$. Both this study and that of Bajerska-Jarzębowska et al. [13] provide evidence that depending on the stage of the annual training cycle athletes representing the same sport discipline may differ significantly in the case of the TEE and DEE and in the ratio between them.

As far as international studies are concerned, the study of Japanese track and field athletes conducted by Motonaga et al. [19] is noteworthy. In the study, participants' heart rate was recorded for $24 \mathrm{~h} /$ day to assess their daily and training energy expenditure. The TEE and DEE of 6 middle- and long-distance runners aged 19-21 years old were measured on days 1, 6, 8 and 10 of an 11-day observation period during the preparatory cycle. Their mean TEE estimated at $2255 \pm 658 \mathrm{kcal}$ accounted for $49.3 \%$ of their DEE. The average daily energy intake amounted to $4514 \pm 739 \mathrm{kcal} /$ day.

In 2 studies involving Kenyan long-distance runners, participants' DEE was estimated at an average of 3605 \pm $119 \mathrm{kcal}$ [28] and $3492 \pm 249 \mathrm{kcal}$ [23]. In other studies on endurance athletes (rowers, long-distance swimmers, triathlon racers), the mean values of the DEE amounted to $4824 \pm 773 \mathrm{kcal}$ [24], $4080 \pm 638 \mathrm{kcal}$ [29], and $3846 \pm$ $580 \mathrm{kcal}$ [30]. In this study, the mean DEE of endurance athletes was $4518 \pm 717 \mathrm{kcal}$.

The absolute values of the DEE calculated during the preparatory phase of training for female athletes in this study are significantly lower (by around 1200-1300 kcal/day) from those obtained for male athletes. The authors of international studies with female long-distance runners estimated their mean DEE at 2990 $415 \mathrm{kcal}$ [31], $2938 \mathrm{kcal}$ [32], $2629 \mathrm{kcal}$ [33], $2467 \mathrm{kcal}$ [6] and $2099 \mathrm{kcal}$ [34]. In this study, the DEE of a female $3000 \mathrm{~m}$ steeplechase runner ranged $2023-2743 \mathrm{kcal}$, with a mean of $2341 \pm 336 \mathrm{kcal}$. A higher mean DEE, $3036 \pm 179 \mathrm{kcal}$, was obtained for a female middle-distance runner. Hill and Davis [22] who analyzed 7 female rowers aged $20 \pm 1.1$ years old estimat- 
ed their mean DEE at $3957 \pm 1219 \mathrm{kcal}$. In this study, the DEE of female endurance athletes varied between $2023 \mathrm{kcal}$ and $4958 \mathrm{kcal}$, with a mean of $3217 \pm 554 \mathrm{kcal}$.

The mean DEE and TEE values that Woodruff and Meloche [26] obtained for the members of the Canadian women's intercollegiate volleyball team were $3479 \pm$ $603 \mathrm{kcal}$ and $511 \pm 216 \mathrm{kcal}$, respectively. Ojrzanowski et al. [35] who studied the members of the Academic Sports Association of the Academy of Physical Education (Akademicki Związek Sportowy Akademii Wychowania Fizycznego - AZS AWF) in Warsaw (women's volleyball team) estimated their energy cost at $541 \pm 99 \mathrm{kcal}$ for a training session of $2 \mathrm{~h}$ and $647 \pm 126 \mathrm{kcal}$ for a 3 -h session. Daily energy expenditure without basal metabolism proved playerspecific and ranged 900-1800 kcal. In this study, the DEE calculated for the women's premier volleyball league team ranged from $2121 \mathrm{kcal}$ (non-training days) to $3829 \mathrm{kcal}$ (a day with 2 training sessions). The mean DEE was $3233 \mathrm{kcal}$ and average energy cost amounted to $714 \mathrm{kcal}$, with the average duration of a training session of $160 \mathrm{~min}$. It is quite obvious that sport disciplines have their specific profiles of physical effort, training and training cycle, which may contribute to variations for athletes' TEE and DEE. This study, as well as other studies cited above, shows that an athlete's sex, BM and body composition may cause significant differences in the TEE and DEE of not only athletes representing different sports, but also between athletes in the same sport. The stages of the annual training cycle that differ in training intensity and volume also have a differentiating effect.

The comparison of energy intake standards for PALs presented by Jarosz [27] and the actual DEE levels of the athletes showed that PAL 2.4 was the most appropriate for 10 athletes ( 4 women and 6 men), PAL 2.2 - for 8 athletes ( 5 women and 3 men), PAL 2.0 - for 2 female athletes, and PAL 1.75 - for 2 women and 1 men. The DEE of the remaining 7 athletes ( 2 women and 5 men) corresponded best with energy intake standards for athletes de- veloped by Celejowa [2]. In the study of basketball players conducted by Silva et al. [25], physical activity levels varied from 2.2 to 3.7 , with a mean of $2.8 \pm 0.4$.

The above findings lead to a conclusion that using the general energy intake standards created for athletes and/or physically active people as the only reference in designing nutritional strategies for athletes may expose the latter to energy imbalance problems. Such problems are likely, when athletes' actual demand for energy intake and the standards differ significantly from each other. Therefore, athletes should be monitored for energy expenditure to determine the amount of energy intake they really need.

\section{CONCLUSIONS}

Training energy expenditure and the DEE levels proved to differ significantly among athletes from different sports as well as between athletes in the same sport. This indicates the need to monitor the real energy expenditure of individual athletes.

The mean absolute values of energy expenditure of male and female athletes were not related to the nature of their sport. The special demands of particular sport disciplines did not cause significant differences between the mean DEE of endurance and power athletes.

Male athletes and female athletes engaged in endurance and power sports have similar levels of the TEE (with a tendency for slightly higher levels among endurance athletes).

In most cases, the lowest energy cost was associated with strength training and the highest with endurance training. The mean DEE and TEE differed significantly because of athletes' sex and were higher for male athletes.

Groups of athletes formed according to athletes' sex and the type of sport had significantly different relative energy expenditure (in relation to $\mathrm{BM}$ ).

The mean values of female athletes' DEE corresponded best to the general daily energy intake standards for PAL 2.2. For the male athletes, PAL 2.4 standards were the most appropriate. 
Energy intake required by individual athletes and the recommendations of nutritional standards may be significantly different from each other. Using energy intake standards developed for athletes as the single basis for planning nutritional strategies carries a risk of miscalculating the necessary caloric intake and of occurrence of energy imbalance problems.

\section{REFERENCES}

1. Loucks AB. Energy balance and body composition in sports and exercise. J Sports Sci. 2004;22(1):1-14, https://doi.org/10. 1080/0264041031000140518.

2. Celejowa I. [Nutrition in sport]. Warszawa: PZWL; 2008. p. 28-31,79-138. Polish.

3. Rodriguez NR, Di Marco NM, Langley S. American College of Sports Medicine position stand. Nutrition and athletic performance. Med Sci Sports Exerc. 2009;41(3):709-31, https:// doi.org/10.1249/MSS.0b013e31890eb86.

4. Arieli R, Constantini N. [Energy balance among female athletes]. Harefuah. 2012;151(2):82-5. Hebrew.

5. Ainslie PN, Reilly T, Westerterp KR. Estimating human energy expenditure. A review of techniques with particular reference to doubly labelled water. Sports Med. 2003;33(9):68398, https://doi.org/10.2165/00007256-200333090-00004.

6. Eisenmann JC, Wickel EE. Estimated energy expenditure and physical activity patterns of adolescent distance runners. Int J Sport Nutr Exerc Metab. 2007;17(2):178-88, https://doi. org/10.1123/ijsnem.17.2.178.

7. Can S, Gündüz N, Arslan E, Biernat E, Ersöz G, Kilit B. Multiinstrument assessment of physical activity in female office workers. Int J Occup Med Environ Health. 2016;29(6):93745, https://doi.org/10.13075/ijomeh.1896.00710.

8. Boyle PM, Mahoney CA, Wallace WF. The competitive demands of elite male field hockey. J Sports Med Phys Fitness. 1994;34(3):235-41.

9. Boulay MR, Simoneaus JA, Bouchard C, Boulay MR, Simoneaus JA, Bouchard C. Monitoring high-intensity endurance exercise with heart rate and thresholds. Med Sci Sports
Exerc. 1997;29(1):125-32, https://doi.org/10.1097/00005768199701000-00018.

10. Hedelin R, Wiklund U, Bjerle P, Henrikson-Larsen K. Short-term overtraining: Effects on performance, circulatory responses, and heart rate variability. Med Sci Sports Exerc. 2000;32(8):1480-4, https://doi.org/10.1097/00005768200008000-00017.

11. Pichot V, Roche F, Gaspoz JM, Enjolras F, Antoniadis A, Minini P, et. al. Relation between heart rate variability and training load in middle-distance runners. Med Sci Sports Exerc. 2000;32(10):1729-36, https://doi.org/10.1097/00005768200010000-00011.

12. Zavorsky GS. Evidence and possible mechanisms of altered maximum heart rate with endurance training and tapering. Sports Med. 2000;29(1):13-26, https://doi.org/10.2165/0000 7256-200029010-00002.

13. Bajerska-Jarzębowska J, Jeszka J, Kisiel K. [Assessment of energy expenditure race-walkers during different periods of training]. Wych Fiz Sport. 2002;1(1):357-8. Polish.

14. Achten J, Jeukendrup AE. Heart rate monitoring: Applications and limitations. Sports Med. 2003;33(7):517-38, https://doi.org/10.2165/00007256-200333070-00004.

15. Hiilloskorpi HK, Pasanen ME, Fogelholm MG, Laukkanen RM, Mänttäri AT. Use of heart rate to predict energy expenditure from low to high activity levels. Int J Sports Med. 2003;24(5):332-6, https://doi.org/10.1055/s-2003-40701.

16. Crouter SE, Albright C, Bassett JR. Accuracy of Polar S410 heart rate monitor to estimate energy cost of exercise. Med Sci Sports Exerc. 2004;36(8):1433-9, https://doi. org/10.1249/01.MSS.0000135794.01507.48.

17. Keytel LR, Goedecke JH, Noakes TD, Hiiloskorpi H, Laukkanen R, van der Merwe L, et al. Prediction of energy expenditure from heart rate monitoring during submaximal exercise. J Sports Sci. 2005;23(3):289-97, https://doi.org/10. 1080/02640410470001730089.

18. Chatterjee P, Banerjee AK, Majumdar P, Chatterjee P. Energy expenditure in women boxing. Kathmandu Univ Med J (KUMJ). 2006;4(3):319-23. 
19. Motonaga K, Yoshida S, Yamagami F, Kawano T, Takeda E. Estimation of total daily energy expenditure and its components by monitoring the heart rate of Japanese endurance athletes. J Nutr Sci Vitaminol. 2006;52(5):360-7, https://doi. org/10.3177/jnsv.52.360.

20. Rodrigues VM., Ramos GP, Mendes TT, Cabido CE, Melo ES, Condessa LA, et al. Intensity of official futsal matches. J Strength Cond Res. 2011;25(9):2482-7, https:// doi.org/10.1519/JSC.0b013e3181fb4574.

21. Wilson G, Sparks SA, Drust B, Morton JP, Close GL. Assessment of energy expenditure in elite jockeys during simulated race riding and a working day: Implications for making weight. Appl Physiol Nutr Metab. 2013;38(4):415-20, https://doi.org/10.1139/apnm-2012-0269.

22. Hill RJ, Davies PS. Energy intake and energy expenditure in elite lightweight female rowers. Med Sci Sports Exerc. 2002;34(11):1823-9, https://doi.org/10.1097/00005768-20021 1000-00020.

23. Fudge BW, Westerterp KR, Kiplamai FK, Onywera VO, Boit MK, Kayser B, et al. Evidence of negative energy balance using doubly labelled water in elite Kenyan endurance runners prior to competition. Br J Nutr. 2006;95(1):59-66, https://doi.org/10.1079/BJN20051608.

24. Drenowatz C, Eisenmann JC, Carlson JJ, Pfeiffer KA, Pivarnik JM. Energy expenditure and dietary intake during highvolume and low-volume training periods among male endurance athletes. Appl Physiol Nutr Metab. 2012;37(2):199-205, https://doi.org/10.1139/h11-155.

25. Silva AM, Santos DA, Matias CN, Minderico CS, Schoeller DA, Sardinha LB. Total energy expenditure assessment in elite junior basketball players: A validation study using doubly labeled water. J Strength Cond Res. 2013;27(7): 1920-7, https://doi.org/10.1519/JSC.0b013e31827361eb.

26. Woodruff SJ, Meloche RD. Energy availability of female varsity volleyball players. Int J Sport Nutr Exerc Metab. 2013;23(1):24-30, https://doi.org/10.1123/ijsnem.23.1.24.
27. Jarosz M. [Nutrition standards for the Polish population Amendment] [Internet]. Food and Nutrition Institute; 2012. [cited 2015 Jun 16]. Available from: https://ncez.pl/upload/ normy-net-1.pdf. Polish.

28. Onywera VO, Kiplamai FK, Boit MK, Pitsiladis YP. Food and macronutrient intake of elite Kenyan distance runners. Int J Sport Nutr Exerc Metab. 2004;14(6):709-19, https:// doi.org/10.1123/ijsnem.14.6.709.

29. Drenowatz C, Eisenmann JC, Pivarnik JM, Pfeiffer KA, Carlson JJ. Differences in energy expenditure between highand low-volume training. Eur J Sport Sci. 2013;13(4):42230, https://doi.org/10.1080/17461391.2011.635707.

30. Petridou A, Lazaridou D, Mougios V. Lipidemic profile of athletes and non-athletes with similar body fat. Int J Sport Nutr Exerc Metab. 2005;15(4):425-32, https://doi.org/10. 1123/ijsnem.15.4.425.

31. Edwards JE, Lindeman AK, Mikesky AE, Stager JM. Energy balance in highly trained female endurance runners. Med Sci Sports Exerc. 1993;25(12):1398-404, https://doi. org/10.1249/00005768-199312000-00014.

32. Beidleman BA, Puhl JL, De Souza MJ. Energy balance in female distance runners. Am J Clin Nutr. 1995;61(2):303-11, https://doi.org/10.1093/ajcn/61.2.303.

33. Tomten SE, Høstmark AT. Energy balance in weight stable athletes with and without menstrual disorders. Scand J Med Sci Sports. 2006;16(2):127-33, https://doi.org/10.1111/j.16000838.2005.00451.x.

34. Ismail MN, Wannudri W, Zawiah H. Energy expenditure studies to predict requirements of selected national athletes. Malays J Nutr. 1997;3(1):71-81.

35. Ojrzanowski A, Leszczyńska M, Bartnikowska E. [Using actigraphs to evaluate the energy expenditure of young women practicing volleyball]. Med Sport. 2007;23:41. Polish.

This work is available in Open Access model and licensed under a Creative Commons Attribution-NonCommercial 3.0 Poland License - http://creativecommons.org/ licenses/by-nc/3.0/pl/deed.en. 